\title{
DESENVOLVIMENTO DAS EMOÇÕES MORAIS: COMO AS CRIANÇAS EXPRESSAM E COMPREENDEM SUAS EMOÇÕES E VALORES?
}

\author{
DEVELOPMENT OF MORAL EMOTIONS: HOW DO \\ CHILDREN EXPRESS AND UNDERSTAND THEIR \\ EMOTIONS AND VALUES?
}

Simone dos Santos Paludo ${ }^{1-5}$

Sílvia Helena Koller

PALUDO, S.d.S; KOLLER, S.H. Desenvolvimento das emoções morais: como as crianças expressam e compreendem suas emoções e valores? Rev Bras. Cresc. Desenv. Hum., São Paulo, 13(2): 35-45, 2003.

Resumo: O desenvolvimento emocional infantil é um tópico de grande interesse para a ciência psicológica. As emoções estão presentes desde o nascimento e permeiam toda a vida dos seres humanos. Responder questões sobre como as crianças expressam e compreendem suas emoções e valores são extremamente importantes para o entendimento do desenvolvimento cognitivo, social, moral e emocional dessas. A emoção tem um papel fundamental na formação do senso moral, uma vez que incentiva o comportamento moral e contribui para o desenvolvimento de valores. Na última década, houve um aumento no interesse pela base afetiva do desenvolvimento moral, especialmente no estudo das expressões das emoções morais propriamente ditas. Este artigo apresenta algumas idéias e reflexões sobre o papel e a influência das emoções no comportamento moral, revisando estudos de uma nova corrente teórica do desenvolvimento moral.

Palavras-chave: desenvolvimento moral; emoções morais; crianças.

O desenvolvimento emocional, moral e social de crianças vem sendo um tópico de grande interesse para a ciência psicológica. Várias questões têm sido respondidas e muitas outras ainda inquietam os pesquisadores e interessados na área. Como e quando as emoções e os valores morais são expressos e compreendidos pelas crianças? Estes fenômenos psicológicos ocorrem simul- taneamente com relação às própnas emoções? Como se dá a internalização de valores de outras pessoas? Essas conquistas revelam a notável capacidade das crianças de lidar com as suas própnas emoçoes, assim como perceber as emoções de outras pessoas. Essas são apenas algumas questões que permeiam esse misterioso mundo infantil. Entretanto, teóricos estão explorando ainda

1 Universidade Federal do Rio Grande do Sul. Endereço para correspondência: CEP-RUA/UFRGS, instituto de Psicologia, Rua Ramiro Barcelos 2600/604, CEP 90035-003, Porto Alegre, RS. Fone: (51) 3316-5150, Fax: (51) 3241-0074. E-mail: cep rua ufrgs.br

2 Apoio Capes.

3 As autoras agradecem a participação dos bolsistas de iniciação Cientifica do Grupo de Estudos sobre Emoções morais e desenvolvimento em situação de risco do CEP-RUA/UFRGS.

4 Este estudo faz parte das atividades de Mestrado em Psicologia do Desenvolvimento (UFRGS) da primeira autora, orientada pela segunda autora.5. Simone Paludo é Psicóloga, Mestranda em Psicologia do Desenvolvimento do Curso de Pós-Graduação em Psicologia do Desenvolvimento da Universidade Federal do Rio Grande do Sul. Membro do Centro de Estudos Psicológicos sobre Meninos e Meninas de Rua (CEP-RUA/UFRGS). Coordenadora da Equipe de Pesquisa sobre Emoções morais c desenvolvimento em situação de risco do CEP-RUA UFRGS.Silvia Helena Koller é Psicôloga, Doutora em Educação (PUCRS), Pesquisadora do CNPq e Prot'essora do Curso de PósGraduação em Psicologia do Desenvolvimento da Universidade Federal do Rio Grande do Sul. Coordenadora do Centro de Estudos Psicológicos sobre Meninos e Meninas de Rua (CEP RUA/UFFGS). 
mais em busca de respostas a estas intrigantes questões acerca do desenvolvimento afetivo e de sua relação com o desenvolvimento moral infantil (ARSÊNIO \& KRAMER, 1992; COLE, BARRET \& ZAHN-WAXLER, 1992; DAMON, 1988; DUPLO, 1988; HARRIS, 1989; KAGAN, 1981, 1987).

O papel da emoção no estudo da moralidade tem ocupado um espaço importante nos estudos atuais. As emoções foram consideradas a base da moralidade por alguns filósofos (HUME, 1739/1969; SMITH, 1759/1966), e são enfatizadas presentemente pela ciência psicológica. Algumas teorias recentes propõem que a moralidade é influenciada, principalmente, pelas emoções (DUNN, 1988; KAGAN, 1987; KOCHANSKA, 1993, 1994), contrastando com as teorias tradicionais que enfatizam os aspectos cognitivos, tais como, raciocínio e julgamento para o desenvolvimento nesta área (PIAGET, 1977; KOHLBERG, 1976; TURIEL, 1983). Esse artigo pretende apresentar o papel e as influências das emoções no comportamento moral. Para tal, fazse necessário apresentar algumas das principais idéias sobre desenvolvimento moral e a sua relação com as emoções, que vêm sendo enfatizadas pela literatura.

De uma maneira geral, as emoções podem ser definidas como um estado afetivo produzido pelas respostas fisiológicas e avaliações cognitivas que motivam uma ação (EKMAN, 1992). Já o desenvolvimento moral pode ser definido como o processo pelo qual a criança adquire modelos de certo e errado. Pesquisas afincam que as emoções ajudam as pessoas a distinguir valores em contextos específicos, motivam o comportamento moral e inibem o comportamento imoral (EISENBERG, 2000). As emoções, denominadas morais, consistem em orgulho, vergonha, culpa, constrangimento e inveja. Essas emoções são reguladoras do comportamento moral. LEWIS, SULLIVAN, STANGER e WEISS (1989) sugarem que o desenvolvimento das emoções autoconscientes é derivado em parte, do desenvolvimento das capacidades cognitivas e das experiências de socialização das crianças (ALLESANDRI \& LEWIS, 1996).

Para HAIDT (2000), as emoções morais são respostas às violações morais ou aquelas que motivam o comportamento moral. Considerou duas características para identificá-las: os aliciadores desinteressados e as tendências a ações prósociais. Os aliciadores desinteressados são caracterizados pela ocorrência de eventos, sejam esses bons ou ruins, que conseqüentemente provocarão algum tipo de emoção. Essas emoções podem ser provocadas por diferentes eventos. A emoção provocada motivará algum tipo de tendência em resposta ao evento aliciador. A tendência pró-social refere-se ao engajamento da pessoa em decisões que beneficiem outras pessoas ou apoiam a ordem da sociedade. Assim, quanto mais desinteressados forem os aliciadores, e quanto mais tendências pró-sociais apresentarem, mais prototípicas serão as emoções morais. Por exemplo, dois irmãos, Pedro e Mateus, estavam brincando com blocos de montar, até que Mateus, o irmão mais velho, perdeu a paciêneia com Pedro pois ele estava tendo dificuldades para encaixar os blocos, e os derrubou. Enraivecido, Pedro começou a chorar. Ao perceber a dor de seu inmão, Mateus sentiu-se culpado e tentou amenizar a situação pedindo desculpas ao irmãos que chorava copiosamente. O evento aliciador, neste episódio, foi a dificuldade de Pedro para montar os blocos. Nesse caso o fato é um aliciador desinteressado ou seja, não teve a intenção intrínseca de provocar algum tipo de emoção ao inmão Mateus. Mas, as emoções motivaram a ação de derrubar os blocos como uma resposta ao evento aliciante. A emoção de raiva e choro provocada em Pedro motivou Mateus a ajudar o seu irmão, reparando sua atitude anterior. Dessa forma, a emoção provocada motivou Mateus a aumentar a sua tendência a se engajar em certas ações pró-sociais.

O episódio descrito demonstra claramente a relação entre as emoções morais e o conseqüente comportamento moral das crianças. Assim, é possível confirmar a inter-relação entre moralidade e emoções, uma vez que as emoções morais emergem durante situações moralmente conflitivas e possibilitam a compreensão do desenvolvimento moral das crianças. Os modelos de certo e errado, compreendidos no processo de desenvolvimento moral, são internalizados gradualmente nos anos iniciais. Muitos teóricos importantes, entre eles, Freud, Piaget, Kohlberg, Bandura, Turiel, Eisenberg e Shweder, consideram a internalização como um aspecto fundamental do desenvolvimento moral. Várias teorias do desenvolvimento psicológico humano (psicanalíticas, cognitivas e comportamentais) apresentam conceitos explicativos do desenvolvimento moral, enfatizando os três componentes básicos da moralidade: afeto, comportamento e cognição.

As teorias psicanalíticas enfatizam os aspectos afetivos do desenvolvimento moral, à medida que, assumem que o tipo de relação emocional da criança com seus pais determinará a sua disposição para internalizar os padrões parentais de certo e errado. FREUD (1930/1953) sugere que o senso moral desenvolve-se como resultado de uma forte identificação parental, ou seja, a partir da resolução do Complexo de Édipo. Então, atra- 
vés dessa identificação, a criança intennaliza alguns dos complexos padrões de comportamento, traços pessoais e características, motivações, normas morais, valores e proibições que regem as atitudes dos pais. Esses códigos de conduta internalizados formam o superego. Em contraste, a teoria da aprendizagem social propõe uma doutrina da especificidade, ou seja, acreditam que o comportamento moral depende mais da situação do que da internalização de princípios morais. As crianças adquirem regras e padrões internos por meio da imitação de modelos e pela compreensão das explicações dos agentes socializadores sobre a moralidade e seu significado social. BANDURA (1997) definiu o comportamento moral como uma classe de respostas socialmente aceita, que são auto-reforçadas ou instrumentadas para evitar culpa, ansiedade ou punição. Argumentou que respostas morais ou hábitos são adquiridos da mesma forma que qualquer outro tipo de comportamento social através da aprendizagem. Reconheceu, mais tarde, que as crianças devem alcançar um certo nível de cognição e emitirem comportamentos morais mais especializados antes de compreenderem certos tipos de raciocínio moral, como admite Piaget. Assim, à medida que as crianças crescem, tornam-se mais hábeis e competentes.

A teoria cognitiva enfatiza os aspectos morais relacionados ao raciocínio, focalizando as mudanças que ocorrem a partir do desenvolvimento do pensamento e da inteligência da criança. PIAGET (1977/1932) foi o primeiro a investigar a moralidade sob uma perspectiva cognitiva e evolutiva. Dedicou-se à análise do aparecimento e o estabelecimento das regras em jogos infantis, buscando compreender o comportamento das crianças diante de um sistema de regras. Segundo ele, "toda moral consiste num sistema de regras e a essência de toda moralidade deve ser procurada no respeito que o indivíduo adquire por essas regras" (PIAGET, 1977, p. 11), acreditava que o entendimento das regras morais e convencionais pelas crianças teria que corresponder ao seu nível geral de desenvolvimento cognitivo. Piaget propos dois estágios evolutivos no desenvolvimento do raciocínio moral da criança: heteronomia e autonomia. O estágio de heteronomia caracteriza-se pelo predomínio do respeito unilateral, do realismo moral e da responsabilidade objetiva. Nesta fase, a criança possui uma concepção de regra como algo exterior à consciência e imposta pelo adulto. As ações são julgadas em função da responsabilidade sobre a gravidade ou o prejuízo causado, desconsiderando as intenções e motivos. A partir dos oito anos de idade, inicia a fase autônoma, na qual as crianças começam a intensificar os julgamentos de acordo com as intenções e, não somente, pelas conseqüências. Nesta fase, emerge a cooperação, possibilitadora do surgimento do respeito mútuo e da responsabilidade subjetiva.

O psicólogo americano Kohlberg estendeu o trabalho de Piaget sobre o julgamento moral, para incluir a adolescência e a idade adulta e, também, como Piaget, atribuiu um papel fundamental à evolução do raciocínio. KOHLBERG (1969/ 1976) propôs que a moralidade progride em uma seqüência hierárquica e invariante de três níveis morais, cada qual composto por dois estágios distintos. De acordo com Kohlberg, a ordem desses estágios é invariante, porque depende do desenvolvimento de habilidades cognitivas. Neste sentido, a evolução do pensamento lógico e a consolidação das operações formais são condições necessárias para a emergência do desenvolvimento moral. Assim, procurou determinar os estágios universais no desenvolvimento dos julgamentos morais, propondo aos participantes dilemas morais na fonna de histórias. As respostas a eles são analisadas com base nos motivos apresentados para a decisão tomada frente aos dilemas, e não baseadas em se a ação é julgada como certa ou errada.

De acordo com psicólogos cognitivos desenvolvimentalistas (Piaget, Kohlberg, Turiel), o desenvolvimento moral é um processo racional e cognitivo, no qual a criança constrói um código moral por si mesma, baseada nas interações com pares. Dessa forma, os adultos e as figuras de autoridade não transmitem regras e normas diretamente, uma vez que a moralidade da criança é autoconstruída a partir da cultura que a cerca. Entretanto, TURIEL (1983), ao contrário de Kohlberg, afirma que as crianças bem pequenas já são capazes de distinguir meras convenções sociais de princípios morais obrigatórios. Em seus experimentos, NUCCI e TURIEL (1978) afirmaram que as crianças julgam os aspectos morais e os convencionais baseados no prejuízo causado. As ações que causam prejuízos intrínsecos para outros são reconhecidos como errados, e as regras que previnem essas ações são entendidas como necessárias e universais.

As teorias de Piaget, Kohlberg, Bandura e Turiel explicam o julgamento moral focalizando seus aspectos cognitivos, tais como, raciocínio e julgamento moral. Entretanto, a partir de 1980, houve um aumento no interesse pela base afetiva do desenvolvimento moral, especialmente no estudo das expressões das emoções morais propriamente ditas. Dessa forma, surgiram muitos trabalhos relevantes sobre o papel das emocões morais no comportamento moral. Algumas pesquisas transculturais inicialmente desenvolvidas por 
SHWEDER, MAHAPATRA e MILLER (1987), demonstraram que as reações emocionais são, freqüentemente, melhores preditoras de julgamentos morais. HAIDT, KOLLER e DIAS (1993) confirmaram estes achados.

SHWEDER e colaboradores (1987) propuseram a "teoria da comunicação social" para o desenvolvimento moral, cujo pressuposto básico enfatiza que a expressão de emoções pelos pais revela o que é moralmente importante à criança. Estas prestam atenção à fala, à expressão e ao tipo de situação nas quais os adultos demonstram suas emoções, capturando a informação cognitiva e emocional que estão impregnadas nesta expressão. A partir dessas pistas emocionais, as crianças determinam o domínio da moralidade e as respostas apropriadas às violações morais. SHWEDER e colaboradores (1987) sugeriram que o domínio da moral, diferentemente de KOHLBERG (1976), varia de cultura para cultura e não é universal. Demonstraram que muitas culturas tendem a moralizar diferentes grupos particulares dos aspectos sociais, baseados em três concepções de self, a ética da comunidade, da autonomia e da divindade. Cada ética é baseada em conceitualizações diversas da pessoa, ou seja, como possuidora de um grande empreendimento coletivo e interdependente (comunidade), como uma estrutura individual (autonomia) ou como uma entidade espiritual (divindade). Assim, o modelo apresentado por Shweder envolve uma abordagem intuicionista, a qual sugere que o julgamento moral é causado por intuições morais, que são avaliações rápidas e espontâneas, seguidas no tempo pelo raciocínio moral, após alguma elaboração. Segundo HAIDT (2001), as intuições morais, incluindo as emoções morais, aparecem imediatamente após um determinado evento e condicionam os julgamentos morais de acordo com as influências sociais e culturais para o grupo ou comunidade no qual o indivíduo está inserido.

HAIDT, KOLLER e DIAS (1993) conduziram um estudo para verificar os pressupostos do modelo social intuicionista de Shweder e colaboradores (1987), no que diz respeito à variação cultural do domínio moral. Examinaram as respostas de brasileiros e americanos, de diferentes níveis socioeconômicos, frente a ações ofensivas e desrespeitosas, mas não prejudiciais, como por exemplo, limpar o banheiro com a bandeira nacional ou comer o cachorro de estimação após morto. Os resultados indicaram variações culturais e socioeconômicas no domínio da moralidade. Os participantes americanos de alto nível socioeconômico exibiram julgamentos baseados em convenções sociais ou preferências pessoais, assumiram que as ações de desrespeito não são moralizadas, ou seja, não apresentam conseqüên- cias prejudicais interpessoais. Enquanto que os grupos de nível sócio econômico baixo, especialmente os brasileiros, julgaram como morais as ações de desrespeito. Diante destes achados, argumentaram que algumas culturas permitem que os julgamentos morais estejam relacionados com asserções intuitivas ou afetivas (por exemplo, "isto está errado, porque isto é repugnante”), entretanto, em outras culturas o julgamento é baseado na razão (por exemplo, "isto pessoalmente me incomodaria, mas isto não está errado"). Dessa forma, os autores encontraram fortes evidências de que o julgamento moral pode ser resultado de uma intuição moral e em outras, resultado do raciocínio moral. Confirmam assim, a importância das reações emocionais (intuição/afeto) para um melhor entendimento da moralidade das crianças.

As emoções têm um papel fundamental na vida social, cognitiva e moral das crianças, uma vez que servem para organizar e regular o comportamento. O primeiro ano de vida é de extrema importância na vida emocional do bebê. DARWIN (1965/1872) argumentou que as crianças têm uma capacidade inata para reconhecer expressões faciais da emoção e significá-las, afirmou também que as expressões faciais da emoção são universais. Os estudos transculturais de EKMAN (1973) têm apresentado evidências para essa afirmativa relacionada à universalidade. Segundo HARRI S (1989), os bebês e as crianças podem facilmente reconhecer o que as pessoas sentem, uma vez que os sentimentos são visíveis na face. EKMAN (1992) acredita que as emoções estão presentes no nascimento ou se desenvolvem nos meses após o nascimento e podem ser identificadas pelas expressões faciais que os bebês comunicam. Também concordam que, os bebês experimentam e comunicam seis emoções primárias, quando completam o seu primeiro aniversário alegria, medo, raiva, surpresa, tristeza e nojo.

Por volta de dez semanas, os bebês reagem diferentemente e apropriadamente dependendo da emoção que a mãe expressa. Segundo DARWIN (1965/1872) os bebês reconhecem e respondem ao significado capturado da expressão do cuidador. Assim, no primeiro ano, os bebês ajustam seu comportamento social à emoção expressa pelo cuidador. No final do primeiro ano, estendem essa seletividade para os objetos e fenômenos no ambiente e parecem reconhecer quando o adulto expressa uma emoção frente a um determinado aspecto. Dessa forma, os bebês se aproximam ou evitam o contato com o objeto a partir da mensagem emocional que o adulto expressa (HARRIS, 1989).

Alguns autores consideram o segundo ano de vida como o período de emergência do self; no 
qual a criança inicia a distinção de si próprio e do outro como entidades diferentes, e se percebe como agente de suas ações (KAGAN, 1981,1987; THOMPSON, 1998). Nesta idade, as crianças são sensíveis às proibições parentais, a apreciação de modelos e identificam ações que foram anteriormente consideradas erradas pelos seus pais ou cuidadores. KAGAN (1981) demonstrou que aos dois anos de idade expressavam ansiedade quando percebiam que as pessoas falhavam frente ao modelo esperado. Segundo DUNN (1988), as crianças não só reagem às emoções de outras pessoas, como antecipam a possibilidade de gerar emoções diferentes. Neste período, há uma maior sensibilidade da criança para as intenções e os sentimentos dos outros. Tal sensibilidade é evidente no comportamento conflitante e/ou cooperativo. As crianças começam a provocar emoções, irritando ou confortando outras crianças. Esses esforços para modificar o estado emocional do outro constituem um claro avanço no comportamento.

Estudos recentes confirmam essas transformações no desenvolvimento emocional, social e moral das crianças de dois anos (ARSÊNIO \& KRAMER, 1992; DUNN, BROWN \& MAGUIRE, 1995; LEWIS, SULLIVAN, STÁNGER \& WEISS, 1989; SMETÁNA, SCHALAG-MAN \& ADAMS, 1993). Reações emocionais de crianças de dois anos durante infortúnios foram investigadas por COLE, BARRET e ZAHNWAXLER (1992). Situações, tais como, aquelas que envolviam uma boneca quebrada e derramamento de suco foram focalizadas. $\mathrm{O}$ estudo permitiu abordar o papel da emoção na formação sociomoral da criança, uma vez que descreveu em detalhes a angústia das crianças durante esses episódios, medidos através das expressões faciais e vocais e tentativas de reparação. Entre as principais reações emocionais, COLE e colaboradores (1992) verificaram a presença de emoções negativas, como a tensão e a frustração de forma mais freqüente, no entanto, algumas crianças apresentavam uma tendência de coinpensação e alívio de tensão gerada por sua ação. Segundo estes autores, os estilos de reação das crianças estão intrinsecamente ligados aos estilos emocionais observados na expressão de suas mães. Um achado interessante refere-se às fortes evidências de que as mães com sintomas depressivos e ansiedade provocavam nos filhos respostas mais freqüentes de tensão e de frustração.

Aos três anos, as crianças já compreendem regras sociais e diferenciam certos tipos de transgressão, questionam e discutem diferentes aplicações de regras e demonstram certa compreensão de responsabilidade (DUNN, 1988). Além disso, começam a entender as relações de hierar- quia e autoridade dentro da família. Dessa forma, revela que a compreensão das regras e o seu desenvolvimento moral dependem, em parte, do conhecimento sobre o mundo social no qual ela está inserida. O entendimento das reações emocionais de outras crianças tem um importante papel na sensibilidade ao certo e errado. Essas habilidades parecem emergir nos anos iniciais da infância e, gradualmente, ocorre um processo de internalização de regras e capacidades que permitem regular o próprio comportamento de acordo com modelos de conduta. KAGAN (1981, 1987) propôs que a consciência de modelos e padrões e a sensibilidade às suas violações emergem na metade do segundo ano de vida das crianças e estão associadas a fatores maturacionais e cognitivos. Essa consciência de atos certos e errados determinará o desenvolvimento de outros processos socioemocionais da consciência, como a angústia associada com a violação de padrões de conduta, a vergonha e a culpa.

Alguns autores têm argumentado que a sensibilidade para a violação dos modelos, ou seja, a percepção da criança sobre as ações certas ou erradas, é uma forma inicial de moralidade (KOCHANSKA, CASEY \& FUKUMOTO, 1995). Outros pesquisadores propuseram que a compreensão da criança sobre os modelos de certo e errado, juntamente com as estratégias autoreferenciais, caracterizadas pela habilidade da criança em reconhecer a própria imagem e, conseqüentemente, refletir e avaliar as suas próprias ações, intenções, estados e habilidades de acordo com os padrões sociais, são condições necessárias para o aparecimento das primeiras emoções morais (LEWIS, SULLIVAN, STANGEIR \& WEISS, 1989).

À medida que as crianças tornam-se autoconscientes, ou seja, capazes de agir, pensar e comunicar sobre si mesmas às outras pessoas, emergem novas emoções morais. Tais emoções incentivam o comportamento moral e contribuem para o desenvolvimento de valores. Como as crianças participam de relações sociais desde 0 nascimento, seus pensamentos e emoções morais são conseqüências inevitáveis dessas relações iniciais e de todas as relações que manterão ao longo de suas vidas (DAMON, 1988).

A emoção tem um papel importante na formação do senso moral. A criança pequena ainda não internalizou um princípio moral como um objeto de consciência, mas tem internalizado um senso afetivo que serve para definir a situação como certa ou errada. O significado da moralidade para crianças pode ser mais bem entendido se são sabidas as emoções que as crianças demonstram em situações moralmente relevantes. Geralmen- 
te, as crianças pequenas de quatro e cinco anos não distinguem entre as emoções ditas complexas, elas esperam que o sucesso seja seguido por emoções positivas e a falha por emoções negativas (HARRIS, 1989). Assim, essas crianças entendem que as pessoas possuem objetivos e se sentirão felizes se os alcançarem. Entretanto, crianças mais velhas entendem que a vida emocional nao é regulada somente pela conseqüência das ações, mas também pela consciência das emoções que outras pessoas expressaram. Nas idades entre seis e dez anos as crianças começam a entender as condições em que a vergonha, o orgulho e a culpa são experenciadas. Percebem as pessoas como agentes de seus próprios desejos e como seres sociais, cujas ações são julgadas por si e pelos outros. Começam a compreender que o estado emocional de uma pessoa é influenciado pelo estado emocional de outra. Essa perspectiva traz o estabelecimento de responsabilidade e padrões normativos para ação, uma vez que a aprovação e a desaprovação de outros depende se a criança foi responsável pelo resultado e se o resultado está de acordo com um padrão particular (HARRIS, 1989).

Esses conceitos sobre moralidade e comportamento também foram explorados através da história das xícaras por PIAGET (1977, p. 107). As crianças com menos de sete anos encontramse no estágio denominado como moralidade heterônima, no qual a criança pensa rigidamente sobre conceitos morais, ou seja, acredita que as regras não possam ser mudadas e que o comportamento é certo ou errado e qualquer transgressão merece punição. Dessa forma, as crianças nesse período consideram que o fato de haver derrubado um maior número de copos é mais grave. Entretanto, as crianças mais velhas, que já se encontram no estágio denominado moralidade autônoma possuem maior flexibilidade moral, são menos egocêntricas, e concluem que o certo e o errado são mutáveis. Assim, reconhecem que a criança que derrubou mais copos os derrubou acidentalmente, e que a outra deixou o copo cair, enquanto estava fazendo algo que não deveria.

Alguns estudos têm investigado as emoções morais ou autoconscientes, em crianças e adolescentes. NUNNER-WINKLER e SODIAN (1988) analisaram o desenvolvimento das concepções das crianças de quatro a oito anos de idade sobre as conseqüências emocionais de ações moralmente relevantes. Examinaram as atribuições dessas emoções através de histórias, uma envolvendo a violação de regras morais e outra que envolvia a resistência à tentação. Os resultados indicaram a ocorrência de uma grande mudança entre as idades de quatro a oito anos, uma vez que as crianças de quatro anos, embora conscientes da validade das regras morais, julgavam que o malfeitor deveria experenciar emoções positivas justificadas pelo sucesso alcançado em sua ação, enquanto que as crianças de oito anos julgavam sentimentos negativos justificadas pelo valor moral da transgressão. Entretanto, algumas pesquisas apontam para a existência de diferenças individuais e desenvolvimentais nas concepções de transgressões das crianças.

DUNN, BROWN e MAGUIRE (1995) investigaram 46 crianças do jardim de infância e da primeira série, que já haviam sido investigadas juntamente com suas mães e irmãos de dois e três anos. Os resultados sugerem assoeiações consistentes entre as experiências com mães e irmãos e as respostas de crianças para assuntos morais. Os autores afirmaram que a sensibilidade da criança tem sido atribuída às técnicas disciplinares maternas e as práticas de socialização, embora os achados tenham indicado que as catacterísticas individuais e os processos sociais também influenciam na sensibilidade às regras. Sabe-se que muitas pessoas interagem com as crianças e possuem um papel extremamente importante na formação moral e emocional das mesmas. Essas pessoas podem ser chamadas de "socializadores de emoções", uma vez que apresentam à criança o que é aceitável em sua cultura (DENHAM, 1998). Os pais são os primeiros socializadores, mas os pares têm um papel fundamental na aprendizagem das regras e das emoções ditas complexas. As emoções morais emergem quando a criança aprende modelos, padrões e regras para o comportamento.

Vergonha e culpa são emoções morais que surgem de discrepâncias entre o comportamento e as características da própria pessoa e de seus modelos morais. São freqüentemente confundidas, mas são respostas afetivas distintas a falhas pessoais e transgressões. De maneira geral, a literatura aponta para algumas similaridades entre as emoções de vergonha e culpa (FERGUSON, STEGGE, MILLER \& OLSEN, 1999; TAN-GNEY, MILLER, FLICKER, 1. \& BARLOW, D., 1996; LEITH \& BAUMEISTER, 1998). Ambas referem-se a afetos negativos associados com a auto-avaliação de que algo foi feito errado e estão, freqüentemente, ligadas a transgressões interpessoais ou a situações nas quais as pessoas acreditam ter violado normas do próprio comportamento. Geralmente, também, são usadas na socialização das crianças a fim de ensiná-las a obedecer às normas sociais e tratar outras pessoas de forma socialmente desejável. Uma importante diferença entre as emoções de vergonha e culpa é o foco. A experiência de vergonha é direta sobre o self; o qual é 
foco da avaliação. Já no sentimento de culpa, a ação realizada é o objeto central de avaliação negativa, e não o self (LEWIS, 1971).

A culpa pode ser definida como um sentimento disfórico associado com o reconhecimento de uma violação moral pessoal ou de um padrão social (KUGLER \& JONES, 1992). Pode, também, ser definida como uma emoção baseada na inquietação, na qual a pessoa experencia medo, preocupação, ansiedade, tensão e desejo de reparação aos comportamentos percebidos como violações de modelos internos morais. A culpa envolve, ainda, uma avaliação negativa de um comportamento específico, ou seja, as pessoas sentem remorso, tensão, arrependimento pela má ação que fizeram e sentem necessidade de reparála. Geralmente a culpa é provocada pela avaliação de prejuízo causado, como danos ou ameaças a outros. BAUMEISTER, STILLWELL e HEATHERTON, (1994) concordam que a culpa parece ser uma reação mais forte e poderosa, quando atinge pessoas mais próximas, como pais e amigos. Por exemplo, Aline estava brincando com sua boneca nova, quando seu irmão, Leonardo, começou provocá-la e tomou dela sua boneca e a jogou pela janela. Aline começou a chorar e chamou sua mãe, que repreendeu Leonardo, colocando-o de castigo em seu quarto. Leonardo arrependido do que havia feito, pediu licença à mãe, e foi até a rua procurar a boneca. Devolveu a boneca, pediu desculpas e voltou para o castigo. Nesse exemplo, percebe-se que Leonardo reconheceu a sua transgressão depois de ter recebido uma avaliação negativa de sua ação por parte de sua mãe. Essa repreensão promoveu sentimentos de remorso e uma ação de reparação - recuperar o objeto que havia desprezado. A culpa tem sido considerada uma emoção moral prototípica, pois motiva um comportamento de ajuda à vitima ou motiva o agente a reparar e melhorar as relações com ela e com os outros evitando gerar mais culpa.

LEITÃO (1999) investigou as diferenças sexuais e de idade no sentimento de culpa e responsabilidade pessoal para com outras pessoas. Utilizou uma série de dilemas morais, com finais abertos, para que as crianças pudessem contar a história, descrever os pensamentos, sentimentos, atitudes e motivos dos personagens. As respostas foram analisadas a partir da teoria psicanalítica kleiniana, e os resultados mostraram que os meninos mais novos apresentaram mais respostas de culpa persecutória e menos respostas de culpa depressiva do que os meninos e meninas mais velhos. Além disso, as respostas indicando preocupação por outras pessoas, baseadas em princípios morais, aumentarain com a idade e foram mais freqüentes nos meninos.
Em contraste, a vergonha é uma emoção que envolve sentimentos de desamparo, incompetência e um desejo de escapar e evitar o contato com outras pessoas, envolvendo uma avaliação negativa de si mesmo (FERGUSON E COLS., 1999; LEITH \& BAUMEISTER, 1998). Geralmente, a vergonha é provocada pela percepção do próprio indivíduo de que algo está errado consigo, devido a falhas no cumprimento de modelos morais ou a incompetência. Sendo um comportamento de submissão, a vergonha reduz a presença social das pessoas, criando uma motivação a esconder-se ou retirar-se. Por exemplo, em seu primeiro dia de aula no colégio, Carolina foi pegar seu material escolar para desenhar e deixou cair no chão todos os seus lápis de cor. Todos os colegas começaram a rir de sua "incompetência" e Carolina sentiu-se muito envergonhada e com vontade de sair correndo da sala de aula devido a sua distração. O fato dos colegas "debocharem" da sua falha fez com que Carolina se sentisse envergonhada e humilhada. A avaliação dos colegas foi feita sobre a falha de Carolina e não sobre a sua ação, demonstrando que o sentimento de vergonha é direto sobre a pessoa.

La TAILLE (2002) analisou a relação entre o sentimento de vergonha e a moralidade a fim de demonstrar que a vergonha é um sentimento fundamental, não apenas para a conduta moral dos homens, mas também para o desenvolvimento moral da criança e do adolescente. O autor resgatou e discutiu o papel da afetividade, especialmente o sentimento de vergonha, na moralidade. Em seu estudo, abordou quatro tópicos essenciais para vincular a vergonha e a moralidade: a relação entre o juízo próprio e o juízo alheio, a relação entre a vergonha prospectiva e retrospectiva, os aspectos positivos e negativos da vergonha e 0 lugar do Eu na vergonha. A partir de sua discussão, La Taille demonstrou e fortaleceu a relação entre vergonha e moralidade. Seu estudo confirma a importância dos aspectos afetivos para a compreensão do desenvolvimento moral dos indivíduos.

FERGUSON, STEGGE e DAMHUIS (1991) investigaram as concepções de crianças de sete a doze anos sobre as emoções de culpa e vergonha a partir de uma perspectiva funcionalista. Para tal investigação, os autores realizaram dois estudos. No estudo 1, desenvolveram quatro histórias temáticas sobre transgressão e erros sociais a fim de averiguar a natureza das emoções, as justificativas, o significado da experiência e a tendência de ação das crianças. No estudo 2, utilizaram 36 afirmações referentes às emoções de culpa e vergonha para investigar as concepções das crianças sobre essas emoções. Os resultados su- 
geriram que os sentimentos de culpa são despertados pelas violações a normas morais, enquanto, que os sentimentos de vergonha resultam de transgressões morais e sociais. Dessa forma, os autores afirmaram que essas emoções têm um papel fundamental no desenvolvimento social, uma vez que a culpa promove o comportamento pró-social e inibe o agressivo e a vergonha estimula a conformidade aos modelos de conduta.

Assim como a culpa e a vergonha, a gratidão tem um lugar especial na vida moral, uma vez que resulta e estimula o comportamento moral. MCCULLOUGH, KILPATRICK, EMMONS e LARSON (2001) propuseram uma teoria da gratidão denominando-a de afeto moral, sugerindo três funções morais para a gratidão: barômetro moral (indica uma resposta à percepção de benefício a partir de uma ação moral realizada por outra pessoa), motivo moral (motiva a pessoa grata a comportar-se pró-socialmente em direção ao benfeitor e a outras pessoas) e reforçador moral (encoraja os benfeitores a comportarem-se moralmente no futuro). HAIDT (2000) considera a gratidão como uma emoção moral positiva, e aponta como seus principais oficiadores a percepção de benefícios para si e para outros, motivando comportamentos pró-sociais, como agradecimentos e favores aos benfeitores. Por exemplo, Juliana estava saindo sozinha de casa quando tropeçou e caiu no meio da calçada, torcendo o pé direito. Uma pessoa que estava caminhando do outro lado da calçada viu a menina cair e percebeu que ela estava machucada e foi ao encontro dela oferecer ajuda. Chamou os pais da menina para a levarem ao médico pois podia ter quebrado o seu pé e precisava de atendimentos médicos. Juliana ficou bastante agradecida pelo ato desta pessoa que nem mesmo a conhecia. Depois de alguns dias, Juliana encontrou-se em uma situação parecida, mas dessa vez, sendo ela quem prestaria ajuda a outra pessoa. Assim, a ação de Juliana revela que uma vez beneficiada com algum tipo de ação positiva, a pessoa pode tornar-se mais favorável a comportar-se moralmente no futuro.

Entre as emoções ditas morais podem ser incluídas a empatia e a simpatia. A empatia é uma resposta afetiva que se origina da compreensão do estado emocional do outro, à medida que 0 indivíduo assume um sentimento similar ao qual o outro está sentindo (EISENBERG, 2000). Por exemplo, se uma criança observa um companheiro triste pelo falo de ter sido maltratado por outros, sente-se triste também, devido à condição em que o mesmo se encontra. Desta forma, essa criança experienciou um sentimento de empatia ao colocar-se no lugar do outro e perceber os sentimentos despertados pelo evento. EISENBERG
(2000) define, também, o conceito de simpatia, sugerindo que este é uma resposta emocional originada da compreensão do estado emocional do outro, mas não provoca o mesmo sentimento da outra pessoa como na empatia. A simpatia, freqüentemente, envolve sentimentos de preocupação e interesse.

Os estudos e argumentos apresentados até aqui indicam que a emoção tem um papel essencial no desenvolvimento social e emocional das crianças e, além disso, possibilitam conhecer e compreender a moralidade delas. Essa nova proposta teórica afirma que a moralidade é construída, principalmente, pelas emoções (DUNN, 1987; KAGAN, 1987; KOCHANSKA, 1993, 1994). Além disso, compreende a criança como um indivíduo inserido em uma cultura e um determinado tempo histórico que decide o que é certo e errado através de suas emoções. Embora as emoções sejam constantes e universais, as variações em seu conteúdo moral resultam da interação com o contexto histórico c cultural (KAGAN, 1987). Essa idéia está intimamente ligada à idéia de relativismo do SHWEDER e colaboradores (1987), a qual enfatiza que as emoções incluem as influências culturais como parte da aquisição moral. De acordo com SHWEDER e HAIDT (1993), as emoções revelam características da realidade social. Propõe também que as emoções morais, como a culpa, vergonha e simpatia são combinadas às intuições morais, as quais operam rapidamente, sem necessidade de reflexão e argumentação.

As crianças adquirem a moralidade através da família, da sociedade e da cultura. Os pais têm um papel insubstituível no desenvolvimento moral, a primeira regulação social se dá pela da família, uma vez que esses introduzem as leis, as regras e a lógica social através da autoridade parental e das reações emocionais (DAMON, (1988). As emoções dos pais têm um papel fundamental na comunicação das regras às crianças, ensinam através das expressões faciais e verbais o que é moralmente relevante.

Embora esta área de conhecimento seja recente, já existe um considerável corpo de pesquisa sobre o desenvolvimento normativo do entendimento moral, focalizando os aspectos afetivos (ARSÊNIO \& KRAMER, 1992; DAMON, 1988; HARRIS, 1989; NUNNERWINKLER \& SODIAN, 1988). No entanto, os estudos, em sua grande maioria, focalizam na expressão das emoções primárias pela facilidade empírica de investigação. O método mais utilizado para medir os movimentos de expressões faciais primárias é o Facial Tactil Coding System (FACS) criado por EKMAN e FRIESEN, (1975). Já para as investigações sobre as emoções morais são encontradas 
algumas dificuldades metodológicas devido a escassez de instrumentos psicológicos capazes de medir e investigar as emoções, especialmente as denominadas morais. Essas emoções são mais complexas do que as primárias, são baseadas nas relações com outros e contextos particulares envolvem algum tipo de conflito ou dilema, e são permeadas pelo conhecimento de estruturas do self e do outro. Os métodos mais utilizados para investigar as emoções morais envolvem dilemas morais reais e hipotéticos, observações, cenários hipotéticos e escalas de avaliação (ver FERGUSON \& STEGGE, 1998).

Várias questões sobre a relação entre as emoções e a moralidade têm sido respondidas mas muitas outras ainda inquietam os pesquisadores e interessados na área. Esses fatores apon- tam a necessidade de novos estudos sobre a expressão e o desenvolvimento das emoções morais, especialmente, em diferentes populações e culturas. Poucos estudos, por exemlplo, têm investigado as conseqüências de maus tratos, negligência e abuso no desenvolvimento emocional e moral das crianças (ALESSANDR \& LEWIS, 1996; KOENIG, CICCHETTI \& ROGOSCH, 2000; SMETANA, TOTH CICCHIETTI BRUCE, KANE \& DADDIS 1999). No entanto, essa é uma área emergente para a investigação psicológica. A violência está cada vez mais presente na vida e na família das crianças, seja direta ou indiretamente. $\mathrm{E}$ as consequências desse cotidiano, provavelmente, influenciam e modificam o desenvolvimento moral e emocional dessas crianças e adolescentes.

\begin{abstract}
Emotional development is a topic of great interest for psychological science. Emotions are present since birth and permeate human beings' life cycle. It is extremely important to investigate how children express and understand their emotions and values so as to understand their cognitive, social, moral and emotional development. Emotion has a fundamental role in moral development, moral behavior and values comprehension. In the last decade, the interest in the relation between emotional and moral development, especially in the expressiveness of moral emotions, has increased. This article presents some ideas about the influence of emotions on moral behavio^l; providing a review of studies belonging to the current theory on moral development.
\end{abstract}

Key-words: Moral development; moral emotions; children.

\section{REFERÊNCIAS BIBLIOGRÁFICAS}

ALESSANDRI, S. M.; LEWIS, M. Differences in pride and shame in maltreated and nonmaltreated preschoolers. Child Development, 67: 1857-1869, 1996.

ARSENIO, W.; KRAMER, R. Victimizers and their victims: children's conceptions of the mixed emotional consequences of moral transgressions. Child Development, 63: 915927, 1992.

BANDURA, A. Social learming theory Englewood Cliffs, New Jersey, Prentice Hall, 1997.

BAUMEISTER, R.F.: STILLWELL, A. M.; HEÁTHERTON, T. F. Guilt: an interpersonal approach. Psichological Bulletin, 115: 243267, 1994

COLE, R: BARRET, K.; ZAHN-WAXLER, C. Emotion displays in two-years-olds during mishaps. Chiid Deveiopment, 63: 314-324, 1992.

DAMON, W. The morial child: nurturing children's natural moral growth. New York, Free Press, 1988.

DARWIN, C. The expression of emotions in man and animals. Chicago, University of Chicago Press., 1965. (Original publicado em 1872).
DENHAM, S. Emotional deveiopment in young children. The Guildfoíd Series on Social and Emotional Development. New York, The Guilford Press, 1998.

DUNN, J.; BROWN, J.; MACUIRE, M. The development of children sensibility: individual differences and emotion understanding. Developmental Psichology; 31: 649-65), 1995.

DUNN, J. The beginnings of social understanding. Oxford, Blackwell, 1988.

EKMAN, P. Dariwin and facial expre.ssion. New York, Academic Press, 1973.

EKMAN, P. Are there basic emotions? Psychological Review 99: 550-553, 1992.

EKMAN, .; FRIESEN, W. V. Unmasking the face. Prentice Hall, Englewood Cliffs, 1975.

EISENBERG, N. Emotion, regulation, and moral development. Annual Review Psychoiogy 51: 665-697, 2000.

FERGUSON, T. J.; STEGGE, H.; DAM HUIS, I. Children's understanding of guilt and shame. Child Development, 62: 827-839, 1991.

FERGUSON, T. J.; STEGGE, H.; MILLER, E. R.; OLSEN, M. E. Guilt, shame, and symptoms in children. Deveiopmental Psychology, 35: 347-357, 1999. 
FERGUSON, T. J.; STEGGE, H. Measuring guilt: a rose by other name still has thorns. In: BYBEE, J. (Org.). Guilt and children. San Diego, Academic Press, 1988 p. 10-74

FREUD, S. Civilization and its discontents. In: J. STRACHEY,J. (Ed. e Trad.). The standard edition of the complete psychological works of Sigmund Freud. London, Hogarth Press, 1953. (Original publicado em 1930).

HAIDT, J. The emotional dog and its rational tail: a social intuitionist approach to moral judgment. Psychological Review, 108: 814834, 2001.

HAIDT, J. The moral emotions. In: DAVIDSON, R. J.; SCHERER, K.; GOLDSMITH, H. H. (Orgs.). Handbook of affective sciences. Oxford, Oxford Univ. Press, 2000.

HAIDT, J.; KOLLER, S. H.; DIAS, M. Aftect, culture and morality, or is it wrong to eat your dog? Journal of Personality and Social P.sychology; 4: 613-628, 1993.

HAIDT, J. The emotional dog and its rational tail: a social intuitionist approach to moral judgment. Psychological Review, 4: 814-834, 2001.

HARRIS, P. Children and emotion. The development of psychological understanding. Basil, Blackwell, 1989.

HUME, D. A treatise of human nature. London, Penguin, 1969. (Original publicado em $1739 i$ 174()).

KAGAN, J. Thesecondyear. Cambrige, MA, Harvard University Press, 1981.

KAGAN, J. The nature of child. New York, Basic Books, 1987.

KOCHANSKA, G. Toward a synthesis of parental socialization and child temperament in early development of conscience. Child Development, 64: 325-347,1993.

KOCHANSKA, G. Beyond cognition: Expanding the search for the early roots of internalization and conscience. Developmental Pychology, 30: 2022, 1994.

KOCHANSKA, G.; CASEY, R. J.; FUKUMOTO, A. Toddlers'sensivity to standard violations. Child Development, 66: 643-656, 1995.

KOENIG, A.; CICCHETI, D.; ROGOSCH, F. Child compliance/noncompliance and maternal contributors to internalization in maltreating and non-maltreating dyads. Child Development, 71: 1018-1032, 2000.

KOHLBERG L. Moral stages and moralization: the cognitive-development. In: LICKONA, T. (Org.). Moral development and behavior. theory, research and social isses ( pp. 31 -53). New York, Holt, Rinehart \& Winston, 1976.
KUGLER, K.; JONES, W. H. On conceptualizing and assessing guilt. Journal of Personality and social Psychology, 62: 318-327, 1992.

LA TAILE, Y. O sentimento de vergonha e suas relações com a moralidade. Psicologia: Reflexão e Crítica, 15: 13-25 2()02.

LEITÃO, H. Diferenças sexuais no desenvolvimento da preocupacão moral por outras pessoas: um estudo empírico da expressão das emoções morais. Psicologia Reflexão e Crítica, 1: 1 - 13, 1999.

LEITH, K.; BAUMEISTER, R. F. Empathy, shame, guilt and nanratives of interpersonal conflicts: guiltprone people are better at perspective taking. Journal of Personality, 66: 2-37, 1998.

LEWIS, H. B. Shame and guilt it neurosis. New York, Intennational Universities Press, 1971.

LEWIS, M.; SULLIVAN. M. W.; STANGER, C.; WEISS, M. Self development and selfconscious emotions. Child Development, 60: 146-156, 1989.

MCCULLOUGH, M. E.; KILPATRICK, S. D.; EMMONS, R. A.; LARSON, D. B. Is gratitude a moral affect? Psychological Bulletin, 2: 249266, 2001.

NUCCI, L.; TU RI EL, E. Social interactions and the development of social concepts in preschool children. Child Development, 49: 400-407, 1978.

NUNNER-WINKLER，G.; SODIAN, B. Children's understanding of moral emotions. Child DeveIopment, 59: 1323-1338, 1988.

PIAGET, J. O julgamento moral na crianca. (Trad. Elzon Lenardon) São Paulo, Editora Mestre Jou, 1977. (Original publicado em 1932).

SMETANA, J.; SCHLAGAMAN, N.; ADAMS. P. Preschool children's judgments about hypothetical and actual transgressions. Child Development, 64: 202-214, 1993.

SMETANA, J.; TOTH, S.: CICCHETTI, D.; BRUCE, J.; KANE, R; DADDIS, C. Maltreated and nonmaltreated preschooler's conceptions of hypothetical and actual moral transgressions. Developmental Psychology, 35: 269-281, 1999.

SMITH, A. The theory of moral sentiments. New York. Kelly, 1966. (Orig. publicado em 1759).

SHWEDER, R. A.; MAHAPATRA, M.; MILLER, J. Culture and moral development. In: Kagan, J.; Lamb, S. (Orgs.). The emergency of morality in young children (p, 1-83). Chicago, University of Chicago Press, 1987.

SHWEDER, R.; HAIDT, J. The future of moral psychology: truth, intuition, and the pluralist way. Psychological Science, 4. 360-356, 1993. 
TANGNEY, J. P.; MILLER, R. S.; FLICKER, L.; BARLOW, D. H. Are shame, guilt and embanassment distinct emotions? Journal of Personality and Social Psychology, 70: 12561269, 1996.

THOMPSON, R. Early sociopersonality development. In: DAMON, W.; N. EISENBERG, N. (Orgs.). Handbook of child psychology (p. 25104). New York, John Willey \& Sons, 1998.
TURIEL, E. The development of social knowledge. Moralithy and convention Cambridge, Cambridge University Press, 1983

Recebido em 19/08/2003

Modificado em 21/08/2002

Aprovado em 30/08/2003 